\title{
Application of intelligent orienteering based on Internet of things
}

\author{
Donghui Zhang ${ }^{1 *}$ and Ruijie Liu $^{2}$
}

\footnotetext{
* Correspondence: zdh@jit.edu.cn 'Department of Physical Education, Jinling Institute of Technology, Nanjing 211169, Jiangsu, China Full list of author information is available at the end of the article
}

\begin{abstract}
Orienteering has gradually changed from a professional sport to a civilian sport. Especially in recent years, orienteering has been widely popularized. Many colleges and universities in China have also set up this course. With the improvement of people's living conditions, orienteering has really become a leisure sport in modern people's life. The reduced difficulty of sports enables more people to participate, but it also exposes a series of problems. As the existing positioning technology is relatively backward, the progress in personnel tracking, emergency services, and other aspects is slow. To solve these problems, a new intelligent orienteering application system is developed based on the Internet of things. ZigBee network architecture is adopted in the system. ZigBee is the mainstream scheme in the current wireless sensor network technology, which has many advantages such as convenient carrying, low power consumption, and signal stability. Due to the complex communication environment in mobile signal, the collected information is processed by signal amplification and signal anti-interference technology. By adding anti-interference devices, video isolators and other devices, the signal is guaranteed to the maximum extent. In order to verify the actual effect of this system, through a number of experimental studies including the relationship between error and traffic radius and the relationship between coverage and the number of anchor nodes, the data shows that the scheme studied in this paper has a greater improvement in comprehensive performance than the traditional scheme, significantly improving the accuracy and coverage. Especially the coverage is close to 100\% in the simulation experiment. This research has achieved good results and can be widely used in orienteering training and competition.
\end{abstract}

Keywords: Internet of things technology, Cross country sports, Location Services, Zigbee network

\section{Introduction}

Orienteering, also known as walking orienteering means that competitors use the map and North needle to choose their own route, and then find the points marked on the map in turn, and the person with the shortest time wins. Orienteering is a kind of sports activity which combines the ability of map recognition, map application, and running. It is usually carried out in forest, suburb, and city park, but it can also be carried out in school campus. The army is the forerunner of orienteering. In order to

(c) The Author(s). 2020 Open Access This article is licensed under a Creative Commons Attribution 4.0 International License, which permits use, sharing, adaptation, distribution and reproduction in any medium or format, as long as you give appropriate credit to the original author(s) and the source, provide a link to the Creative Commons licence, and indicate if changes were made. The images or other third party material in this article are included in the article's Creative Commons licence, unless indicated otherwise in a credit line to the material. If material is not included in the article's Creative Commons licence and your intended use is not permitted by statutory regulation or exceeds the permitted use, you will need to obtain permission directly from the copyright holder. To view a copy of this licence, visit http://creativecommons.org/licenses/by/4.0/. 
distinguish the direction under the complex terrain conditions such as mountains and forests, the army is the forerunner of orienteering. They need to choose the road, improve the cross-country ability, maintain the correct direction, and perform the duty of defending the motherland. The term "direction" first appeared in 1888, referring to the participants' crossing of unknown territory with the help of map and North needle. In history, the real orienteering competition was held in the barracks of Stockholm, Sweden and Oslo, Norway, in 1896, which marked the birth of Orienteering as an operation. Orienteering began in 1918, when a Swedish Boy Scout leader named guillant organized a "treasure hunt game," which aroused great interest of the participants. The first official orienteering was held in Scandinavia in 1919, and the sport has a history of nearly 100 years. Orienteering, as a sport, began in northern Europe at the beginning of the last century. By the 1930s, orienteering had established itself in Finland, Norway, Sweden, Denmark, and other countries. The first world orienteering competition was held in 1932. In 1961, the International Orienteering Federation was established in Copenhagen, Denmark. It has 63 member countries.

At present, there are many researches on orienteering at home and abroad, but as a kind of sports, the current research focus is still on the training program. In recent years, the training program of orienteering has made a great breakthrough, gradually making the sport more civilian, rather than exclusive to professional athletes. For the entertainment-oriented cross-country sports, it is faced with different physical fitness and sports experience of participants, especially in different environments, people's response and coping ability are different. When it comes to a wide range of maps with complex terrain, this is often a test for novice participants. Orienteering can exercise our will and enhance our friendship, but at the same time, it faces various risks. When the participants are injured or unable to continue for other reasons, we should quickly locate the players in time. At present, there is little research on cross-country positioning, and the scheme used now is relatively backward. There are often problems such as inaccurate positioning and untimely information transmission. To solve these problems, this paper will develop a set of intelligent applications based on the Internet of things architecture, which is suitable for orienteering.

First of all, the core concept of orienteering is described in detail. This paper introduces the origin of the sport and its current development, and analyzes the form and characteristics of orienteering. The core of the intelligent system studied in this paper is the Internet of things technology. With the rapid development of this technology in recent years, it has been widely used in various fields, and the positioning service of the Internet of things is one of the cores of this technology. Location service plays an important role in many applications of the Internet of things, from personnel tracking, emergency services to asset management, driving navigation, it can cover almost all aspects of the Internet of things applications. For the development of intelligent system, ZigBee network architecture is adopted in this paper. This technology has many advantages in wireless sensor network design, such as convenient carrying, low power consumption, and signal stability. In this paper, the design and implementation of intelligent orienteering of the Internet of things are described in detail, and its advantages and disadvantages are shown while the technical principle is explained. In order to verify the actual effect of the system, the relevant experimental research is established in the end of this paper. In the experiment, the traditional BP neural network 
system and the system in this paper are used for comparative analysis. The experimental data shows that the coverage and accuracy of the system in this paper have been greatly improved, and the comprehensive performance has been further optimized [1-3].

\section{Related concepts and basic theories of this paper}

\subsection{Orienteering}

Orienteering can be traced back to the eighteenth century. It has a history of 100 years. At that time, orienteering mainly focused on outdoor activities. By the 1930s, orienteering had been established in Finland, Norway, Sweden, Denmark, and other cities. In 1961, the International Federation of mentoring organizations was established in Copenhagen with 63 member states. The actual competition was held in Stockholm, Sweden, and Oslo, Norway, in 1895, marking orienteering as a sporting event. Early orienteering is mainly a means that people are forced to take for survival. With the improvement of people's living conditions, orienteering has really become a leisure sport in modern life. As a new sport, orienteering refers to athletes using North needle and map to find the location of each point on the drawing, and reach all points in the shortest time to win the game. Orienteering is not only an entertainment activity, but also a competitive sport. In addition to carrying maps and directions, orienteering does not need any special equipment, and there are no restrictions on participants. Compared with other sports, this is a relatively economic sport, and it is suitable for different people of different ages [4-6].

\subsection{Development form and characteristics of orienteering}

Nowadays, there are various forms of orienteering, but the most basic ones are walking orienteering, relay orienteering, skiing orienteering, night orienteering, $100 \mathrm{~m}$ orienteering, special route orienteering, and 5-day orienteering [7-9]. At present, orienteering has the following four characteristics.

\subsubsection{Universality of participants}

The purpose of sports is to let the whole people participate, share health and happiness, and choose a meaningful and valuable sport to meet the requirements of sports. Orienteering can be held at different levels according to the gender and age of each athlete. Because the duration of orienteering can be long or short, orienteering is a mass sport with comprehensive physical strength and intelligence, suitable for men, women, old and young. Generally speaking, as long as a certain physical quality can participate, the difficulty can also be adjusted at any time according to the participants.

\subsubsection{Entertaining and social}

In orienteering, athletes search each checkpoint in the order of points on the map. In this process, each athlete can choose his own route or cross the terrain, which is more interesting and initiative than running. In addition, orienteering competitions are often arranged in parks, wild areas, and forests, so athletes can not only enjoy the charm of orienteering, but also enjoy the natural scenery. At the end of the competition, athletes exchange experience in the direction and route selection of the whole competition, further reducing the friendly relationship between athletes. At present, this kind of sports 
mode is also widely used in team building and friendship competition, which is a good communication sport. Especially in international competitions, international sports exchanges have been strengthened and personal international friendship has been established.

\subsubsection{Fierce competition}

The charm of sports competition is to win in the competition field through the competition among athletes. The competition characteristics reflected in the competition process are basically all sports. However, orienteering depends not only on physical strength, but also on intelligence and skills. The speed and endurance of running depend on the strength of the body, and the right direction and route selection depend on the ability to see a map and use a pointing needle. Therefore, orienteering not only tests a person's physical quality, but also exercises his psychological and comprehensive judgment ability. Especially, the people who play the leading role in the team often need higher comprehensive quality to lead the team to win.

\subsubsection{Popularization of knowledge}

Orienteering is of great significance to improve people's ability to read and use pictures and enhance their international competitiveness. Li KaShing once said: "knowledge changes fate, struggle can achieve the future, young people must strengthen the cultivation of knowledge ability in their learning career." Teenagers' orienteering can not only adjust their learning mood, strengthen their physique, enrich their geographical knowledge, but also cultivate their self-survival ability in outdoor activities or strange cities. It has certain military significance for the military police, police, and rescue personnel to carry out this campaign and help them to complete the tasks of marching, fighting, reconnaissance and search and rescue. It can be said that orienteering is a very practical sport, which is more comprehensive for the test of participants, rather than a single force, or speed, which is more beneficial for young people, especially for their character growth.

\subsection{Overview of the Internet of things}

In 2009, the Chinese government proposed the "PERCEPTION of China" plan, vigorously supported the development of the Internet of things industry and promoted the development of the Internet of things industry chain as a new industry to the strategic position of China's development. On 7 August 2009, Wen visited the Internet of things technology research and development center of the Chinese Academy of Sciences in Wuxi. He especially pointed out that the core technology should be broken as soon as possible, and the sensor technology should be combined with China's $3 G$ technologies. At the 2010 NPC and CPPCC sessions, Premier Wen Jiabao proposed to "accelerate the development and application of the Internet of things" in the work report of the government. Due to the attention of the government, the Internet of things began to enter the public life gradually. Internet of things is a network based on computer technology, which connects all things through RFID tag technology, wireless data communication, and other technologies. Its essence is to realize the automatic identification of goods (commodities) and the Internet sharing of information through the Internet of 
things by using radio frequency identification technology. The timely sharing of information is one of the core technologies of the Internet of things [10-12].

\subsection{Overview of location services of the Internet of things}

Location service of the Internet of things is one of many applications of the Internet of things. Location service plays an important role in many applications of the Internet of things. From personnel tracking, emergency services to asset management, driving navigation, it can almost cover all aspects of the Internet of things applications. Location service, also known as location service, is a kind of value-added service related to location information, which combines mobile communication network with various location technologies. The location information of Internet of things terminals (such as altitude, longitude, and latitude) is obtained through certain positioning technology and transmitted to location service users or management system, so as to realize various services based on location information. At present, the Internet of things positioning service has been applied to various scenarios, including asset management, personal positioning, tracking query, etc. the service can identify the location information of a person or asset, such as determining the current location of a specific person or asset, or querying the current vehicle location information and its track in a specific time. In addition, businesses can also push targeted information through different locations of current users, including personalized weather information, local consumption information, appointment information, etc. In short, with the rapid development of the Internet of things industry, the rapid growth of the global smartphone market and the growing maturity of the mobile Internet market, the demand for location-based services has exploded [13-15].

\section{Design and implementation of Internet of things intelligent orienteering}

\subsection{Design principles}

Because the communication environment of mobile signal is relatively complex, the technology of positioning by communication signals measurement is interfered, which affects the accuracy. Therefore, this paper adopts the design principle of first analyzing CDMA multiple access interference. Because each user in CDMA system uses the same frequency band, it will cause multiple access interference and near far effect. The problem of multiple access interference will have a great impact on the location signal. Usually, power control and other methods are used to reduce the near far effect. However, since multiple base stations are needed to monitor mobile objects, power control is only effective for service base stations. To reduce the influence of NLOS, one of the basic factors affecting wireless location is NLOS, through which more accurate measurement results can be obtained. However, it is difficult to realize Los propagation. In most cases, they are transmitted in the form of refraction and reflection, which affects the characteristics of signal propagation time, arrival field strength, and receiving signal arrival direction. The multipath effect is another important factor to reduce the influence of multipath effect. In the process of wireless signal transmission, due to the existence of reflector and scatterer, the energy amplitude, phase, delay, and other indicators of wireless signal change results in errors in the process of signal transmission. Different multipath components will cause the change of signal value, which will lead to 
signal fading and increase the number of base stations. It is difficult to have multiple positioning base stations at the same time in bad conditions. Even in the environment with many base stations, the line of sight signal cannot be received due to the occlusion of buildings. How to overcome these adverse factors and achieve the technical indicators of value-added services is the premise for the sustainable development of wireless positioning [16-18].

\subsection{Architecture of positioning system}

Based on the characteristics of ZigBee network, a new architecture of mobile device and personnel positioning system is proposed. This chapter mainly designs the hardware of wireless positioning system. Mobile points in wireless sensor networks need to be carried by mobile objects, so mobile points are powered by batteries. According to the requirements of effective configuration and debugging, the gateway node and reference node are designed for FFD. With the combination of wired and wireless communication, considering that the monitoring center is far away from the wireless personal area network, and the optical network has strong communication ability and better anti-interference ability, so the location data of the substation can be transmitted through optical fiber, ZigBee wireless sensor network positioning website. At the same time, it plays the role of coordinator. The router of wireless personal area network is the reference point of the network, and the terminal location is the mobile point [19-21].

\subsection{Design of ZigBee network}

Some simple data is exchanged between the moving point and the reference point. The reference point passes the collected data to the coordination module as the input of the server-side positioning module, and the positioning control module runs on the server. According to the function, it is divided into three sub modules as shown in the figure below, and its structure is shown in Fig. 1

The serial port receives the data collected by the distance measurement module to the PC, and the distance measurement module integrates and processes the distance measurement data received by the serial port according to the algorithm. The positioning calculation control module receives the output of the measurement distance ion

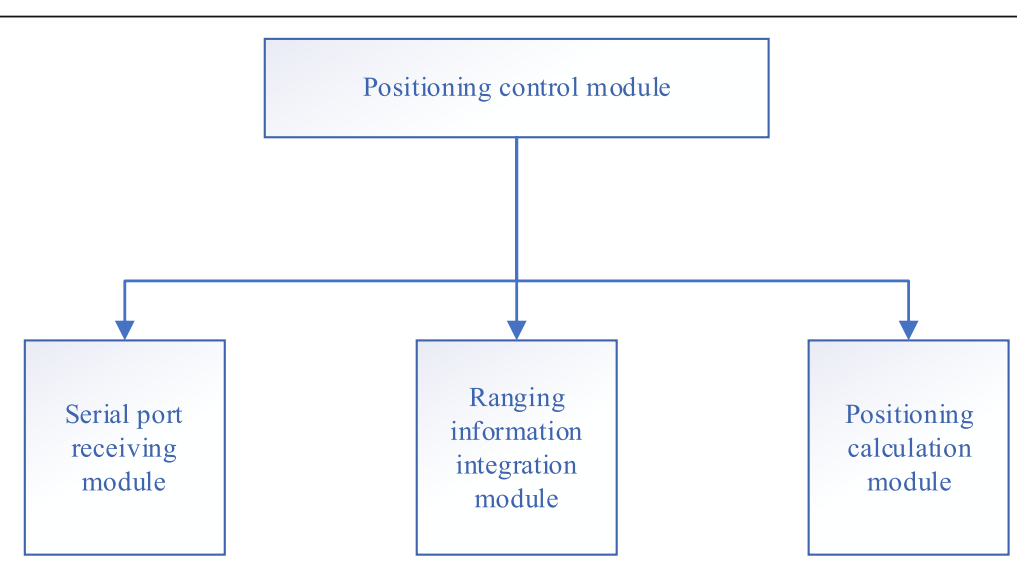

Fig. 1 Schematic diagram of module structure 
module, processes the processed positioning data according to the improved RSSI algorithm, and finally obtains the coordinates of the moving points. In ZigBee wireless sensor location network, there are three types of nodes: mobile node, reference node, and gateway node. Firstly, the location area is selected according to the design requirements, and the reference points are arranged. The router module can route data in the network and provide the terminal with its own location packet containing RSSI value as a reference point. The positioning terminal is carried by a mobile object, which regularly sends packets containing its own ID bits to ZigBee network [22, 23].

\subsection{Mobile node}

The positioning terminal can monitor the environmental parameters by itself with the sensor, which has the characteristics of real-time and mobile. The mobile point is small in size, easy to carry by mobile equipment or waiting personnel, and the terminal is powered by battery. CC2530 chip module is used for the mobile point. Although CC2530 has a $16 \mathrm{MHz}$ RC oscillator, it needs an external crystal oscillator module to ensure the accurate operation of the clock and the stable operation of the RF. When the oscillation is not stable or it is difficult to start, the capacitance of XO terminal can be increased, the ground capacitance of Xi can be reduced, and the feedback can be increased. It can be powered by USB or adapter with few external components, and the prog pin end of tp4056 can be set as constant current charging and current detection terminal [24-26].

\subsection{Reference node}

The reference node has a RF front end and a sensor, and the sensor is randomly arranged to transmit the environmental data obtained, and its position is determined. These nodes can be used as reference coordinates for mobile node positioning, and can be used for data collection and routing functions, usually powered by batteries. The theoretical transmission power of CC2530 can reach $4.5 \mathrm{dbm}$, but sometimes it cannot reach $0 \mathrm{dbm}$. ZigBee router is a fully functional device in the network, which needs to work continuously, so uninterruptible power supply, is used to power ZigBee router.

In this paper, the high integrated RF front-end CC2530 is used to fully meet the application requirements of the devices in the wireless network and expand the communication range of the wireless network. The main characteristics of CC2530 are shown in Table 1.

\subsection{Signal amplification}

Because the collected signal is weak and unstable, it is necessary to amplify the weak or unstable signal through the amplifier to make the received signal stable and reliable. The signal amplifier is mainly arranged in the movement of the mobile station, which

Table 1 CC2530 key characteristics

\begin{tabular}{ll}
\hline Accessible to most RF chips & Up to $\mathbf{1 2} \mathbf{~ d b m}$ output \\
\hline LNA noise coefficient: $4.6 \mathrm{~dB}$ & $25 \mathrm{~mA}$ transmission current \\
$115 \mathrm{~mA}$ transmission current & Improved reception sensitivity \\
Low consumption receiving current mode & Low power consumption, static current in power saving mode \\
\hline
\end{tabular}


is used to amplify the transmission signal of the mobile station. Due to the longer propagation distance in the air, there are more sources of signal interference, so as to ensure the distortion of the received signal at the base station receiver, amplify the signal processing of the signal amplifier, and then pass through the mobile station of the base station $[27,28]$.

In order to realize the "amplification" of the signal, in essence, it is "control." The small energy signal is used to control the power supply to drive the "large energy" so that it changes according to the same change law of the small signal. Thus, the small energy signal is transformed into the large energy signal to realize signal amplification, in other words, information amplification. The circuit that can amplify the current signal is called current amplifier, and the circuit that can amplify the voltage signal is called voltage amplifier. The function of the amplifier is to drive the load, which is called power amplifier. The signal amplifier in this paper is used in the front end of the wireless signal transmitter. In the noise environment, it needs to transmit the signal with high impedance and high common mode suppression ability, so the isolation amplifier circuit is selected.

\subsection{Signal anti-interference technology}

Because there are more than two ground conflicts in the system, there is a certain voltage difference between the ground and the ground. This voltage forms interference current and image interference through the shielding network outside the signal cable. The solution is to use anti-interference equipment with isolation function, such as antiinterference device, video and isolator, or isolate the front-end equipment from the ground, but to avoid the risk of lightning or electric shock [29, 30].

\subsection{Optical fiber transmission network}

Considering the wide range of cross-country movement and the need of long-distance data transmission, the Gigabit Ethernet passive optical network (GEPON) is used to achieve the Gigabit network bandwidth. After the relevant information is collected, it is transmitted to GEPON through technical processing and optical fiber interface, and then GEPON transmits the data to the control platform.

\section{Simulation experiment and result analysis}

In the simulation experiment, the unknown nodes and anchor nodes are randomly distributed in the relevant region $150 \times 150$. This method is compared with the traditional BP neural network location method. One hundred unknown nodes are selected and the radius of the node is $30 \mathrm{~m}$. The average positioning error of the two positioning methods is simulated and tested with different anchor nodes, and compared with the average value of 50 simulation experiments.

Table 2 Comparative analysis of average positioning error rate

\begin{tabular}{lllllll}
\hline Positioning method & \multicolumn{7}{l}{ Average error rate of different anchor nodes (\%) } \\
\cline { 2 - 7 } & $\mathbf{2 5}$ & $\mathbf{3 0}$ & $\mathbf{3 5}$ & $\mathbf{4 0}$ & $\mathbf{4 5}$ & $\mathbf{5 0}$ \\
\hline BP neural network & 45 & 38 & 35 & 30 & 25 & 20 \\
Internet of things intelligence & 25 & 24 & 22 & 20 & 19 & 18 \\
\hline
\end{tabular}




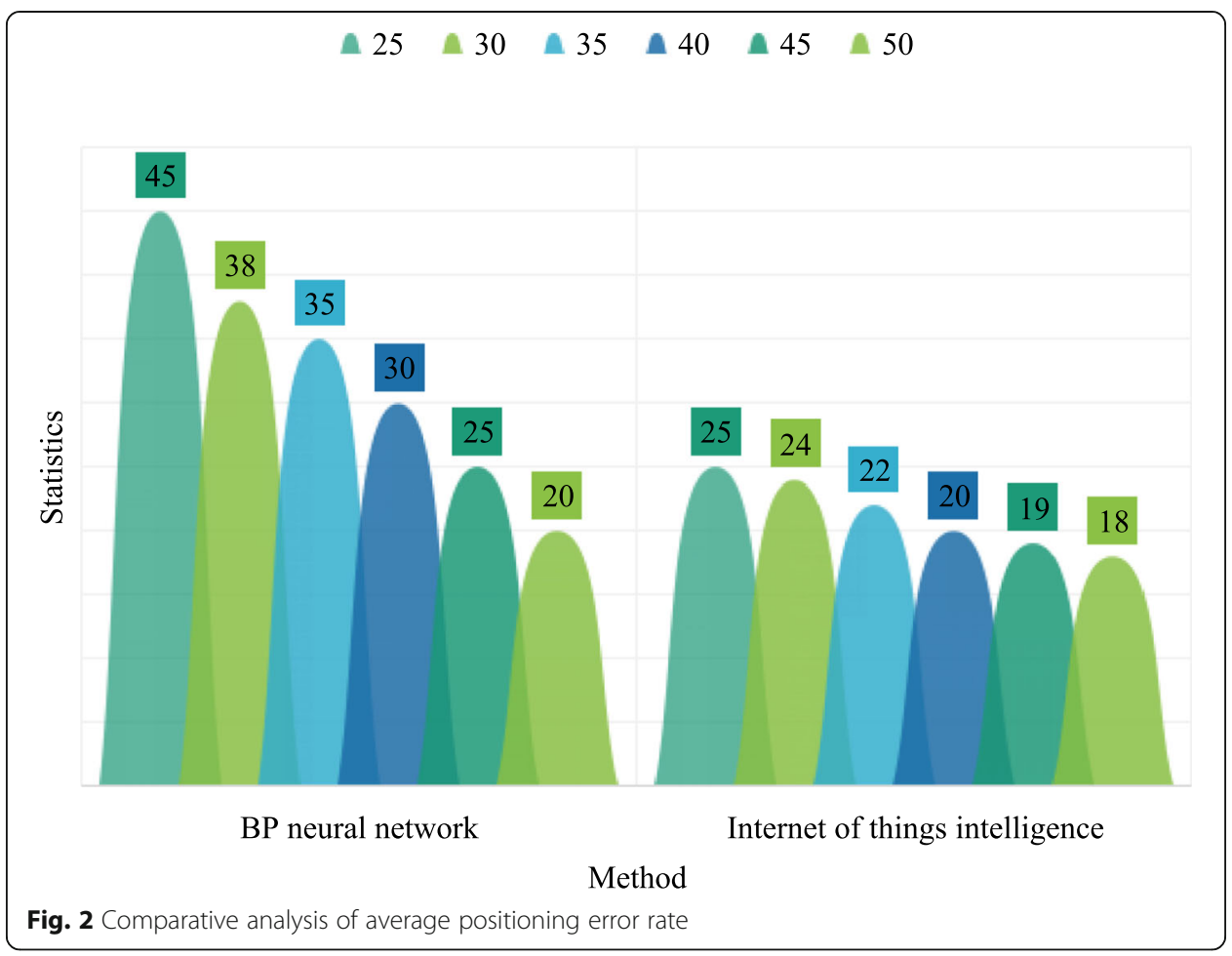

\subsection{Relationship between the error rate and the number of anchor nodes}

According to the results of Table 2 and Fig. 2, with the increase of the number of anchor nodes, the positioning error rate of the two algorithms shows a downward trend. In this paper, the intelligent positioning error rate of the Internet of things is significantly lower than the traditional BP neural network positioning method. Compared with the traditional BP neural network positioning method, the positioning method proposed in this paper increases the average positioning error of nodes to a certain extent. However, with the increase of the number of anchor nodes, the error difference between the two methods decreases gradually, and it is almost the same at 50 points. By comprehensive comparison, the intelligent way of Internet of things in this paper has more advantages.

\subsection{Relationship between coverage and number of anchor nodes}

It can be seen from Table 3 and Fig. 3 that with the increase of the number of anchor nodes in the network, the coverage of these two positioning methods is increasing. However, the coverage of the intelligent location method of the Internet of things in this paper is always higher than that of the traditional BP neural network location method. In addition, when the number of anchor nodes is 50 , the final location

Table 3 Comparative analysis of average location coverage

\begin{tabular}{lllllll}
\hline Positioning method & \multicolumn{6}{l}{ Average coverage rate under different anchor nodes (\%) } \\
\cline { 2 - 7 } & $\mathbf{2 5}$ & $\mathbf{3 0}$ & $\mathbf{3 5}$ & $\mathbf{4 0}$ & $\mathbf{4 5}$ & $\mathbf{5 0}$ \\
\hline BP neural network & 35 & 48 & 56 & 67 & 75 & 82 \\
Internet of things intelligence & 89 & 92 & 93 & 95 & 96 & 99 \\
\hline
\end{tabular}




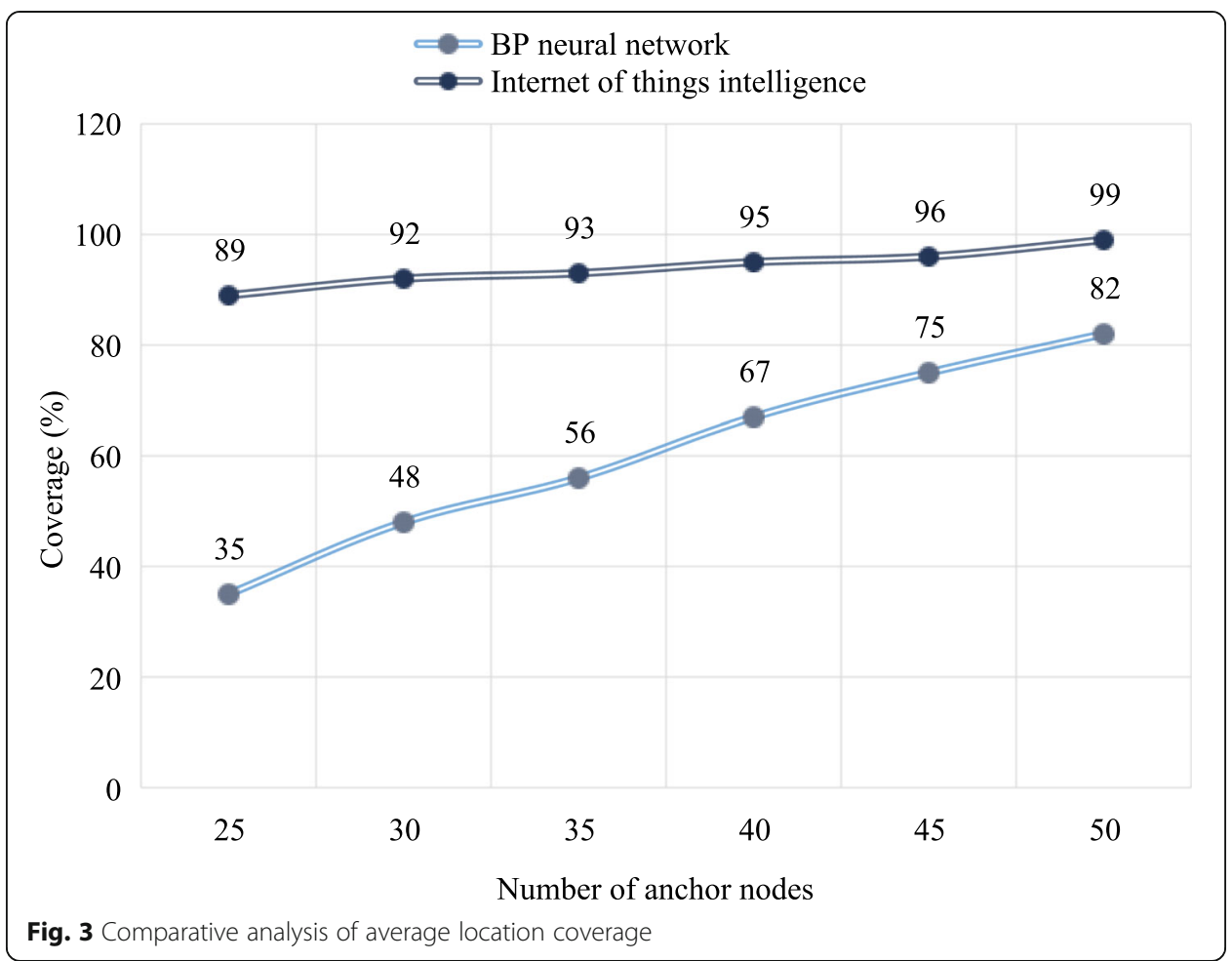

coverage of this method is close to $100 \%$. Therefore, the Internet of things intelligent positioning technology proposed in this paper can improve the shortcomings of traditional BP neural network in positioning coverage, compared with the traditional way, the accuracy has been greatly improved.

\subsection{Relationship between error and passing radius}

It can be seen from Table 4 and Fig. 4 that with the increase of the communication radius of the nodes, the average positioning error rate of the two positioning methods shows a downward trend. When the communication radius is low, the traditional BP neural network location method has a large error, which shows that the location is completely inaccurate. However, with the increase of the number of anchor nodes in the network, the average error value of BP neural network location method began to decline gradually. When the communication radius is greater than 30 , the average error value of the algorithm is not much different from that of the Internet of things intelligent positioning proposed in this paper. However, it is worth noting that the intelligent positioning of the Internet of things proposed in this paper is always better than the traditional method in error rate, which can be improved to prove that this method is significantly better than the traditional method in accuracy rate.

Table 4 Comparative analysis of the relationship between error rate and communication radius

\begin{tabular}{lllllll}
\hline Positioning method & \multicolumn{6}{l}{ Average error rate under different communication radius (\%) } \\
\cline { 2 - 7 } & $\mathbf{1 4}$ & $\mathbf{2 0}$ & $\mathbf{2 4}$ & $\mathbf{2 8}$ & $\mathbf{3 0}$ & $\mathbf{3 2}$ \\
\hline BP neural network & 100 & 89 & 72 & 46 & 26 & 20 \\
Internet of things intelligence & 70 & 63 & 51 & 32 & 25 & 18 \\
\hline
\end{tabular}




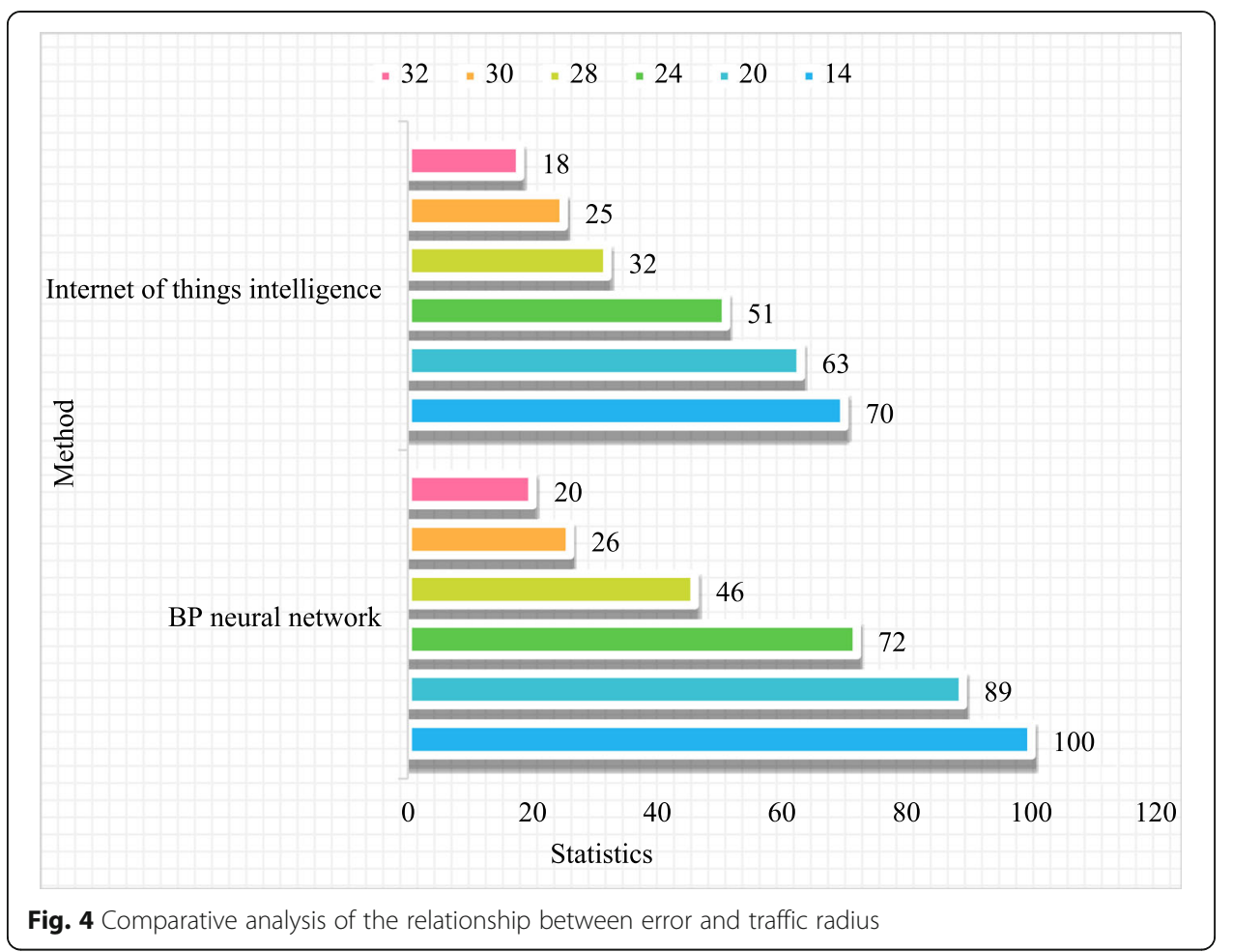

\subsection{Relationship between coverage and communication radius}

It can be seen from Table 5 and Fig. 5 that the average location coverage of the two algorithms increases with the increase of communication radius in the network. The average location coverage of the Internet of things intelligent location method proposed in this paper is always higher than that of the traditional BP neural network location method. When the communication radius of the network is low, it can achieve better location effect. When the communication radius increases to about 30, the location coverage rate of the intelligent location method of cultural relics networking is almost $100 \%$. However, when the coverage of the traditional BP neural network location method is the highest, there is still a big gap between this method and the traditional BP neural network location method. It can be explained that the intelligent location method of the Internet of things in this paper greatly improves the location coverage of traditional methods.

\section{Conclusions}

Orienteering is suitable for different age groups. After entertainment, orienteering has become a popular leisure sport in daily life. It can not only exercise people's will and enhance friendship between partners, but also improve people's bad mood and treat depression. The application system of orienteering based on the Internet of things can

Table 5 Comparative analysis of the relationship between coverage and communication radius

\begin{tabular}{lllllll}
\hline Positioning method & \multicolumn{6}{c}{ Average coverage rate under different communication radius (\%) } \\
\cline { 2 - 7 } & $\mathbf{1 4}$ & $\mathbf{2 0}$ & $\mathbf{2 4}$ & $\mathbf{2 8}$ & $\mathbf{3 0}$ & $\mathbf{3 2}$ \\
\hline BP neural network & 35 & 52 & 61 & 73 & 81 & 85 \\
Internet of things intelligence & 85 & 88 & 90 & 93 & 97 & 99 \\
\hline
\end{tabular}




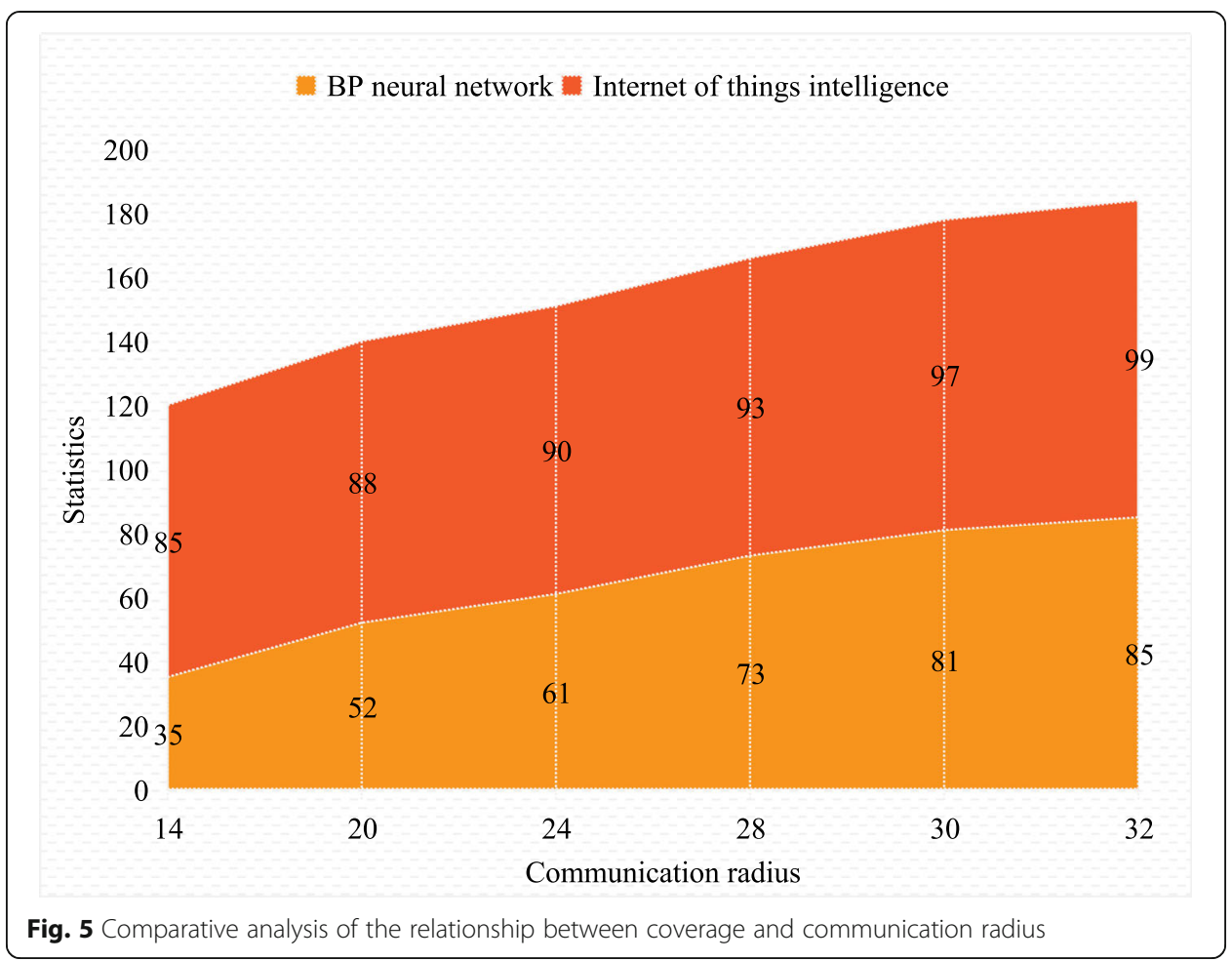

solve the difficult problem of positioning people in the process of sports and provide convenience for emergency services. The system makes full use of the unique sensing layer and transmission layer in the Internet of things technology, and processes the collected information quickly and efficiently, and feeds back to the terminal system. It has the advantages of convenience, easy architecture, low power consumption and stable signal. In this paper, a comparative experiment is used, and the reference object is the traditional BP neural network system. After a number of comparative experiments, through the analysis of experimental data, we can see that the Internet of things technology in this paper has obvious advantages over the traditional technology. In the aspect of error rate, it is always better than the traditional method, and improves the shortcomings of traditional BP neural network in the aspect of location coverage. In this paper, when the coverage is the highest, it almost reaches $100 \%$, which improves the coverage of traditional methods significantly. This experimental study has achieved ideal results, and provides a good research basis for the research of orienteering related positioning.

\section{Abbreviations}

3G: 3rd generation; NPC: National People's Congress; CPPCC: Chinese People's Political Consultative Conference.; RFID: Radio Frequency Identification; CDMA: Code Division Multiple Access; FFD: Full functional device; GEPON: Gigabit Ethernet passive optical network; BP: Back propagation

\section{Acknowledgements}

The authors thank the editor and anonymous reviewers for their helpful comments and valuable suggestions. 
Authors' information

Donghui Zhang was born in Jixi Anhui P.R. China, in 1977. He received the Master degree from Nanjing Normal University P.R. China. Now, he works in Jinling institute of technology, Department of Physical Education, Nanjing, China. His research interests include the traditional sports culture and folk sports.

\section{Funding}

This work was supported by research results of educational reform at school level in Jinling Institute of Technology (JYJG2019-12) and Research on the Construction of Sports Culture in China in the Belt and Road Process (No. 18BTY015).

\section{Consent for publication}

Approved.

\section{Competing interests}

There is no potential competitive advantage in our paper. All the authors have reviewed the manuscript and agreed to submit it to your magazine. We confirm that the contents of the manuscript have not been published or submitted for publication elsewhere.

\section{Author details}

${ }^{1}$ Department of Physical Education, Jinling Institute of Technology, Nanjing 211169, Jiangsu, China. ${ }^{2}$ School of Software, Qufu Normal University, Qufu 273100, Shandong, China.

Received: 19 June 2020 Accepted: 29 September 2020

Published online: 15 October 2020

\section{References}

1. R. Penicka, J. Faigl, P. Vana, M. Saska, Dubins orienteering problem. IEEE Robotics Automation Lett. 2(2), 1210-1217 (2017)

2. C. Verbeeck, P. Vansteenwegen, E.H. Aghezzaf, Solving the stochastic time-dependent orienteering problem with time windows. Eur. J. Oper. Res. 255(3), 699-718 (2016)

3. M. Hansen, J. Bangsbo, J. Jensen, B.M. Bibby, K. Madsen, Effect of whey protein hydrolysate on performance and recovery of top-class orienteering runners. Int. J Sport Nutr. Exerc. Metabol. 25(2), 97-109 (2015)

4. F.F. Colakoglu, B. Cayci, M. Yaman, S. Karacan, S. Gonulate, G. Ipekoglu, et al., The effects of the intake of an isotonic sports drink before orienteering competitions on skeletal muscle damage. J Phys. Ther. 28(11), 3200-3204 (2016)

5. J. Yu, M. Schwager, D. Rus, Correlated orienteering problem and its application to persistent monitoring tasks. IEEE Trans. Robot. 32(5), 1106-1118

6. K. Hébert-Losier, S. Platt, W.G. Hopkins, Sources of variability in performance times at the world orienteering championships. Med. Sci. Sports Exerc. 47(7), 1523-1530 (2015)

7. Y. Mei, F.D. Salim, X. Li, Efficient meta-heuristics for the multi-objective time-dependent orienteering problem. Eur. J. Oper. Res. 254(2), 443-457 (2016)

8. P. Fränti, R. Mariescu-Istodor, L. Sengupta, O-mopsi: mobile orienteering game for sightseeing, exercising, and education ACM Trans. Multimed. Comput. Commun. Appl. 13(4), 1-25 (2017)

9. Z. Tongkuan, D. Shu, On the teaching and practice of "internet plus orienteering" course pattern\%"Internet + Orienteering" course pattern teaching and practice research. J Zhejiang Ocean Univ. (Humanities Edition) 034(005), 73$76(2017)$

10. Y. Jian, G. Jinsong, Design and implementation of intelligent classroom based on internet of things technology. Design and implementation of intelligent classroom based on internet of things technology. China Audio Vis. Educ. (012), 83 (2016)

11. Z. Kaisheng, T. Kaiyuan, L. Ming, L. Chao, Design of agricultural greenhouse environment monitoring system based on internet of things technology\%. Design of agricultural greenhouse environment monitoring system based on Internet of Things technology. J Xi'an Univ. Sci. Technol. 035(006), 805-811 (2015)

12. Z.H. Wu, Research on the application of internet of things technology to digital museum construction. Acta Geosci. Sin. 38(2), 293-298 (2017)

13. Y. Wang, The innovation of computer internet of things technology in logistics field\%. Innovation of computer internet of things technology in logistics field. Logistics Technol 040(003), 41-42 (2017)

14. T. Jiya, J. Feng, Laser detection and control system based on internet of things technology. Laser Magazine 040(003), 153-157 (2019)

15. C. Mingwu, T. Guilin, Non-contact monitoring system for high-temperature industrial furnace based on internet of things technology. J Hebei North Univ. (Natural Science Edition) 035(005), 42-45 (2019)

16. F. Yanru, S. Yunqiang, Research on Zigbee wireless networking technology. Fire Control Radar Technol. 000(003), 69-71 (2015)

17. A. Kumar, G.P. Hancke, A zigbee-based animal health monitoring system. Sensors J. IEEE 15(1), 610-617 (2015)

18. E. Ronen, A. Shamir, A.O. Weingarten, C. Oflynn, lot goes nuclear: creating a zigbee chain reaction. IEEE Security Privacy 16(1), 54-62 (2018)

19. Y. Kim, S.S. Lee, S.K. Lee, Coexistence of zigbee-based wban and wifi for health telemonitoring systems. Biomed. Health Inform. IEEE J. 20(1), 222-230 (2016)

20. L. Yu, W. Wang, C. Runze, Zigbee-based loT smart home system\%the design of internet of things smart home system based on zigbee. Electronic Testing 000(005), 71-75 (2016)

21. Z. Haihong, Z. Jiafeng, Temperature and humidity monitoring system based on zigbeetechnology\%temperature and humidity monitoring system based on zigbee technology. Foreign Elect. Meas. Technol. 000(007), 75-79 (2015)

22. M.M. Ali, K. Youhei, S. Mostafa, C.E. Knox, W. Markus, J. Hyongdoo, et al., Development of underground mine monitoring and communication system integrated zigbee and gis. Mining Sci. Technol (English Version) 025(005), 811-818 (2015) 
23. V.P. Rao, D. Marandin, Adaptive channel access mechanism for zigbee (ieee 802.15.4). J Comm. Software Syst. 2(4), 283$293(2017)$

24. N. Islam, M. Jaminul, H. Biddut, A.I. Swapna, R. Jany, A study on priority based zigbee network performance analysis with tree routing method. J Comp. Comm. 3(3), 1-10 (2015)

25. M. Jun, Q. Deng, Z. Wan, A zigbee wireless network temperature monitoring system based on cc $2530 \%$. Design of zigbee wireless networking temperature monitoring system based on cc2530. Elect. Design Eng. 023(022), 117-121 (2015)

26. F. Xiaodong, Introduction and characteristics of zigbee, uwb and lifi\%zigbee, uwb, lifi three wireless communication technologies and their characteristics. Sci. Technol. Innov. Prod 000(010), 101-103 (2016)

27. X. Yang, Z. Gao, Enzyme-catalysed deposition of ultrathin silver shells on gold nanorods: a universal and highly efficient signal amplification strategy for translating immunoassay into a litmus-type test. ChemCommun 51(32), 6928-6931 (2015)

28. Y. Zhu, H. Wang, L. Wang, J. Zhu, W. Jiang, Cascade signal amplification based on copper nanoparticle-reported rolling circle amplification for ultrasensitive electrochemical detection of the prostate cancer biomarker. ACS Appl. Mater. Interfaces 8(4), 2573-2581 (2016)

29. W.Q. Huang, M. Zhang, D. Wei, D.G. Sun, J. Shi, Efficient and anti-interference method of synchronising information extraction for cideo leaking signal. let Signal Proc. 10(1), 63-68 (2016)

30. A. Bin, Anti-interference analysis of train ground wireless communication transmission subway signal system. Sci. Technol. Innov. Prod (012), 84-85 (2015) 88

\section{Publisher's Note}

Springer Nature remains neutral with regard to jurisdictional claims in published maps and institutional affiliations.

\section{Submit your manuscript to a SpringerOpen ${ }^{\circ}$ journal and benefit from:}

- Convenient online submission

$\checkmark$ Rigorous peer review

- Open access: articles freely available online

- High visibility within the field

- Retaining the copyright to your article

Submit your next manuscript at $\boldsymbol{\nabla}$ springeropen.com 